\title{
CONSTRAINTS ON THE EVOLUTION OF DENTAL FORM IN EARLY CENOZOIC HERBIVORES
}

\author{
RENSBERGER, John M., Department of Geological Sciences and Burke Museum, \\ Box 353010, University of Washington, Seattle, WA 98195.
}

The chewing mechanisms of the Paleocene herbivorous placentals differ substantially from those of their insectivorous ancestors and their later Cenozoic successors. The absence of a linear change from insectivore to advanced herbivore appears to reflect differences in scale and associated constraints.

Increases in size of the masticatory muscles related to large body size greatly elevated maximum chewing forces, which required either new stress-reducing dental shapes or stronger dental materials. As size continued to increase, herbivores would have depended increasingly on food parts that existed in greater abundance (leaves and stems) but which had lower nutrient and higher fiber content, requiring that the teeth impart higher stresses to the material, effect finer mechanical breakdown, and process materials at higher rates. Rapid processing and fine breakdown of fibers are accomplished orally in most later Cenozoic herbivores by multiple occlusal enamel edges aligned transverse to the direction of the chewing stroke.

The dental mechanisms that are actually observed in the early placental herbivores lack the extensive shearing surfaces, intercusp crests, and large cusp height/width aspect ratios typical of insectivores. Sets of parallel striae on abraded surfaces are generally lacking and there is little directionality of the enamel edges bounding worn cusps. Therefore, although the new mechanism utilized the same dominantly vertical jaw movements characteristic of the insectivores, it lacked shearing interaction of opposing surfaces and had become a dominantly compressive mechanism.

This morphology contrasts with the those of the major groups of later Cenozoic and modern herbivores, which have directionally aligned enamel edges, often in multiple rows along the chewing pathway, are marked extensively by parallel striae, and have extensive horizontal or low angle shearing movements.

The replacement of a shearing mechanism by a compressive one in an evolutionary pathway leading eventually to another shearing mechanism may have occurred because the high internal dental stresses associated with shearing exceeded the strength of the enamel, the stiffest of the dental materials and one essential to maintenance of stress-concentrating features of shearing dentitions. This hypothesis predicts that the changes in tooth shape occurred before the acquisition of microstructural decussation in enamel. Although decussation has previously been observed in some early Paleocene arctocyonids, it was absent on one diverse group of Paleocene ungulates and its extent is still poorly known for most Paleocene and early Eocene herbivores. It has recently been found that decussation is only partially developed in the early Eocene horse, Hyracotherium, suggesting that similar or even poorer enamel reinforcement may have been present in other early ungulates. A few Paleocene and Eocene herbivores acquired extensive prism decussation but these mammals (pyrotheres, pantodonts, uintatheres, rhinocerotoids, brontotheres, astrapotheres) were exceptionally large for their time and this accelerated their need for stronger enamel. These mammals also have prominent stress-concentrating shearing crests, presumably enabled by the presence of reinforced enamel. 